\section{ARRIENDO EN PROPIEDAD: ARRAIGO Y VULNERABILIDAD RESIDENCIAL EN EL BARRIO PUERTO DE VALPARAÍSO*}

Adriana Marín Toro ${ }^{\alpha}$

Felipe Link ${ }^{\beta}$

Felipe Valenzuela ${ }^{\gamma}$

\section{Resumen}

Con la actual política habitacional del país y el encarecimiento del valor del suelo, es cada vez más difícil implementar vivienda bien localizada para sectores de bajos ingresos en Chile. Por otro lado, existen recomendaciones internacionales respecto al arriendo como solución a los patrones de segregación espacial que la política de vivienda ha promovido. Sin embargo, los análisis sobre el arriendo y los arrendatarios, como también las políticas públicas vinculadas a este sector, han sido escasos en Chile y Latinoamérica. A través de una lectura de un caso particular, el Barrio Puerto de Valparaíso, que presenta más de un noventa por ciento

\section{TENANCY: ATTACHMENT AND RESIDENTIAL VULNERABILITY IN THE PORT DISTRICT OF VALPARAÍSO*}

\author{
Adriana Marín Toro ${ }^{\alpha}$ \\ Felipe Link ${ }^{\beta}$ \\ Felipe Valenzuelar
}

\section{Abstract}

Current housing policies and the increased price of land hamper the construction of well-located dwellings for low-income groups in Chile. On the other hand, international recommendations propose the leasing of dwellings as a solution to the spatial segregation generated by housing policies. However, the situation of tenants and the activity of leasing as well as the housing policies involved in this sector have been scarcely explored in Chile and Latin America. The case study of the port district of Valparaiso, a site characterized by the development of this type of tenure-where more than 90 percent of 
de arrendatarios y una tradición en este tipo de tenencia de la vivienda, se exploran y describen las dimensiones subjetivas del arriendo vinculadas al arraigo, los sentimientos de pertenencia al hogar y el barrio, más allá de la condición de propiedad del suelo. El artículo releva las características del arriendo, entendido como una situación particular de vulnerabilidad residencial en un contexto específico de producción social del espacio a escala barrial y de presiones por renovación urbana y gentrificación.

PALABRAS CLAVE: VALPARAÍSO, VULNERABILIDAD RESIDENCIAL, ARRAIGO, VIVIENDA EN ARRIENDO; GENTRIFICACIÓN.

Recibido: 15/01/2016

Aceptado: 03/10/2016

* Proyecto mini COES-Centro de estudios de conflicto y cohesión social (COES) "La defensa del lugar y límites de los habitantes de Valparaíso y el Barrio Puerto", año 2014-2015. CONICYT/ FONDAP/15130009.

a Chile. Facultad de Arquitectura y Urbanismo, Pontificia Universidad Católica de Valparaíso. Correo electrónico: amarin@ead.cl

$\beta \quad$ Chile. Instituto de Estudios Urbanos y Territoriales, Pontificia Universidad Católica de Chile. Correo electrónico: felipe.link@ uc.cl

$\gamma \quad$ Chile. Instituto de Estudios Urbanos y Territoriales, Pontificia Universidad Católica de Chile. Correo electrónico: fevalenzuela@uc.cl

128 revista invi 32(90) : 127-157, agosto 2017 dwellers are tenants- explores and describes the subjective dimensions of tenancy associated with attachment and the sense of belonging to the place of residence and the neighborhood, which transcend the type of land ownership. This paper analyses the characteristics of tenancy, which is understood as a specific type of residential vulnerability within a context marked by social production at a neighborhood scale and the pressure exerted by urban renewal and gentrification initiatives.

$\begin{array}{lcr}\text { KEYWORDS: } & \text { VALPARAÍSO, } & \text { RESIDENTIAL } \\ \text { VULNERABILITY, } & \text { ATTACHMENT, } & \text { TENANCY, } \\ \text { GENTRIFICATION. } & & \end{array}$

Received: 15/01/2016

Accepted: 03/10/2016

* This paper is based on the project entitled "Defense of the Place of Residence and Limits of the Inhabitants of Valparaíso and its Port Neighborhood". COES Project, 2014-2015. CONICYT/ FONDAP/15130009.

$\alpha \quad$ Chile. Faculty of Architecture and Urban Planning, Pontifical Catholic University of Valparaíso. Email: amarin@ead.cl.

$\beta \quad$ Chile. Institute of Urban and Territorial Studies, Pontifical Catholic University of Chile. Email: felipe.link@uc.cl.

$\gamma \quad$ Chile. Institute of Urban and Territorial Studies, Pontifical Catholic University of Chile. Email: fevalenzuela@uc.cl. 


\section{Introducción}

"arrendar es botar la plata"

(Hombre, 36 años, arrendatario nuevo)

Una idea generalizada relativa al arriendo, incluso para los propios arrendatarios, es que significa "botar la plata". En Chile, al igual que otros países del mundo, observamos una marcada preferencia por la propiedad privada de la vivienda por sobre otros tipos de tenencia (Gilbert, 1993 y 2011; Wiese, 2004; Reid, 2013; Jiménez y Fernández, 2014). Inclinación que como práctica social, posee dimensiones culturales y limitaciones económicas que van estructurando comportamientos y a su vez, van generando un tipo de arraigo social en determinados grupos de la sociedad. En este contexto, se ha significado a la vivienda como la variable económica más estable a largo plazo, por lo que se va constituyendo en una de las razones de valoración de la propiedad, particularmente en los grupos de bajos ingresos (Sabatini, Brain y Mora, 2012).

En Chile, la proporción de arrendatarios tiende a ser mayor a medida que el nivel socio-económico aumenta (Blanco, Fretes y Muñoz, 2014), aunque sigue siendo una proporción menor con respecto a la vivienda en propiedad. En el caso específico de Santiago, sin embargo, la cifra de arrendatarios ha ido en aumento en los sectores de bajos ingresos.
La población de los deciles más bajos que arrienda en la ciudad lo hace en las áreas centrales, debido principalmente a las redes laborales y sociales que allí se generan. Por lo tanto, este tipo de tenencia no se comprende solo por una demanda por techo, sino más bien por una demanda vinculada a la integración a la ciudad (Mora, s.f.). Así, parece ser habitual que los arrendatarios en Chile y América Latina se ubiquen en las áreas centrales, densas y accesibles en términos urbanos, cuestión observada en Buenos Aires, Lima, Bogotá, Montevideo, Quito y Medellín (Blanco, 2013). A pesar de lo anterior, los arrendatarios no han sido asimilados por las políticas de gobierno a través de sus programas de vivienda (Coulomb y Sánchez, 1991) y las demandas de este grupo por la mejora de la calidad de sus hogares, generalmente no son consideradas por las autoridades (Gilbert, 1993 y 2011). Si a esto se suman bajos ingresos familiares, la vulnerabilidad es evidente, debido a su poca importancia cultural, social y débil protección legal, se trata entonces de un grupo fácil de mover y de desplazar de ciertos sectores de la ciudad, especialmente de aquellos más atractivos, donde el mercado de arriendo económico es altamente sensible a los cambios del contexto urbano (Coulomb y Sánchez, 1991).

Por otra parte, en principio, el arriendo se presenta como una alternativa contra toda razón económica (Reid, 2013), ya que sería la vivienda en propiedad la que tradicionalmente se asocia a seguridad 
social y posesión de capital, así como a otros significados más complejos, como la garantía de un buen mantenimiento general de la vivienda, vecinos de ingresos y educación equivalentes, símbolo de éxito económico y social, entre otros (Wiese, 2004). Sin embargo, la extensión de la propiedad privada de la vivienda para grupos vulnerables, en base a una política de vivienda, tiene como principal desafío la imposibilidad de acceder a suelo bien localizado. No parece suficiente entonces el acceso formal a una casa en propiedad, en un contexto de hiper segregación residencial y extensión urbana (Link, Valenzuela y Fuentes, 2015), donde los valores asociados a la propiedad se van diluyendo.

En este marco, este trabajo pretende conocer, desde una aproximación cualitativa, las dimensiones subjetivas del arriendo para grupos de bajos ingresos a escala barrial, a partir del caso particular del Barrio Puerto, en el contexto de metropolización de la ciudad de Valparaíso, que se encuentra localizado en un área central y presenta un alto porcentaje de arrendatarios. De esta forma, se pretende avanzar en la discusión de un arriendo en propiedad en nuestras ciudades, pues hoy en día simboliza una opción socialmente desvalorizada (Reid, 2013). Los arrendatarios han pasado desapercibidos en el contexto urbano, especialmente aquellos caracterizados por bajos ingresos e informalidad, los cuales son muchas veces invisibles tanto para la política pública como para la literatura académica:
"Se trata de una población que vive bajo la amenaza de la reurbanización o del desahucio, normalmente sin derechos reconocidos sobre indemnizaciones o realojamientos [...] Los inquilinos están dispersos por los asentamientos, con una amplia variedad de contratos informales y con frecuencia ni pueden organizarse como un grupo de presión para protegerse a sí mismos" (Davis, 2007, p. 67).

\section{El Plan de Valparaíso y el arriendo como tenencia en el Barrio Puerto}

Antes de profundizar en las características del arriendo en el Barrio Puerto, es importante tener en cuenta el contexto urbano en el cual se ubica este barrio. Durante las últimas décadas, la comuna de Valparaíso progresivamente ha perdido población a consecuencia de los movimientos migratorios. El resultado de este proceso ha sido el estancamiento de su población, que desde 1982 ha visto prácticamente inalterada su cantidad de habitantes. Sin embargo, el estancamiento a nivel general se expresa en el decaimiento simultáneo de ciertas áreas de la comuna y el crecimiento de otras. Como se observa en la tabla 1 , el sector conocido 
TABLA 1. CANTIDAD DE HABITANTES POR SECTOR DEL ÁREA METROPOLITANA DE VALPARAÍSO (1982-2012)

\begin{tabular}{|lllll|}
\hline & 1982 & 1992 & 2002 & 2012 \\
\hline Plan de Valparaíso & 12.245 & 11.391 & 8.002 & 5.787 \\
\hline Resto de la comuna de Valparaíso & 255.160 & 262.874 & 258.445 & 257.260 \\
\hline Comunas del área metropolitana de Valparaíso & 394.764 & 463.480 & 524.358 & 590.810 \\
\hline Total & 662.169 & 737.745 & 790.805 & 853.857
\end{tabular}

Fuente: Elaboración propia en base a Censo 1982, Censo 1992, Censo 2002 y Levantamiento Censal 2012

como "Plan" de Valparaíso1 (donde se ubica el Barrio Puerto), experimenta un proceso sostenido de decrecimiento desde 1982, lo que contrasta con la tendencia expansiva del área metropolitana.

El notorio proceso de despoblamiento del Plan de Valparaíso constituye un antecedente central para comprender las amenazas que enfrenta actualmente este sector, y ponen en tensión el futuro de un área patrimonial. Se trata de un territorio que si bien concentra buena parte de las actividades comerciales y financieras de la comuna, ha perdido progresivamente el carácter de barrio residencial. Como parte de este proceso, se va diferenciando el perfil del habitante y el tipo de residencia del Plan con respecto al resto de la comuna. En general, se trata de jóvenes entre 20 y 29 años, principalmente estudiantes, así como residentes de tercera edad (Link, Marín Toro y Valenzuela, 2015), que

1 En la figura 1, el Plan de Valparaíso corresponde al sector más oscurecido del mapa. sobrepasan a la distribución comunal y metropolitana en estas categorías. Viven principalmente en viviendas subdivididas, en condición de relativo hacinamiento y mayoritariamente como arrendatarios, como se verá más adelante.

El Plan de Valparaíso se compone de distintos barrios o sectores. Utilizando los distritos censales del Censo de Población y Vivienda es posible distinguir cuatro: el Barrio Puerto, que corresponde al área fundacional de la ciudad; el sector Comercio, que corresponde al centro bancario de la ciudad; el sector Plaza Victoria, que abarca los alrededores de esta plaza; y el Almendral, que es el área de mayor superficie y cantidad de población del Plan de Valparaíso. En el caso del barrio fundacional, este se encuentra en una situación de despoblamiento y deterioro que resulta problemático para la ciudad, sobre todo considerando que se trata de una zona 
patrimonial. Específicamente, el Barrio Puerto tenía en el año 1970 alrededor de 2000 habitantes (I. Municipalidad de Valparaíso, 2009). Hoy la cifra es incierta, pero se estima entre 400 y $1.000^{2}$ personas, de los cuales más de un 90\% son arrendatarios $^{3}$, como se puede observar en la figura 1. La ausencia de datos claros sobre el número de residentes de este sector, refleja la invisible condición de los arrendatarios en este contexto urbano ${ }^{4}$.

La mayoría de estos habitantes reside en departamentos surgidos por la subdivisión informal de viviendas, conocidos tradicionalmente como "conventillos". Los hogares del Barrio Puerto, así como también los del resto del Plan, tienden a estar conformados por una menor cantidad de personas por hogar (2,2 en el Barrio Puerto y 3,1 en la comuna de Valparaíso), con una gran proporción de hogares unipersonales ( $42 \%$ en el Barrio Puerto) en relación con el resto de Valparaíso (15,6\%). Por último, se trata de hogares con un alto porcentaje relativo de hacinamiento (17\%) y que habitan piezas en viviendas con alta subdivisión.

2 La estimación corresponde al CENSO 2002, notas de prensa y entrevistas con actores claves que conocen y habitan el barrio.

3 Según CASEN 2013, levantamiento censal 2012.

4 En ese sentido, el levantamiento censal 2012 presenta una subestimación del número de arrendatarios del Barrio Puerto, catastrando apenas a 195 personas.

5 El "conventillo" de finales del siglo XIX se caracterizaba por un tipo de vivienda deplorable, con las malas condiciones materiales, higiénicas, hacinamiento y condición de pobreza (Urbina, 2011).
Por otro lado, el Barrio Puerto es un lugar central en la distintiva morfología de la ciudad de Valparaíso, ubicado en una zona consolidada, con altos grados de vulnerabilidad social y precariedad, pero emplazado en un sector atractivo para promover proyectos comerciales, de vivienda, que permitan satisfacer nuevas necesidades de consumo (Inzulza, 2012), en un contexto de alta presión por gentrificación (Vergara-Constela y Casellas, 2016) que podría amenazar la permanencia de los residentes actuales, especialmente aquellos de mayor vulnerabilidad residencial.

\section{Arraigo y vulnerabilidad residencial: presiones de renovación urbana y gentrificación}

El presente artículo se basa fundamentalmente en tres conceptos que contribuyen a la comprensión de la dimensión subjetiva del arriendo: el concepto de barrio, arraigo y vulnerabilidad residencial. A continuación se presenta una breve discusión en torno a ellos. 
FIGURA 1. MAPA PORCENTAJE DE HOGARES QUE HABITAN UNA VIVIENDA ARRENDADA. CENSO 2012. COMUNA DE VALPARAÍSO

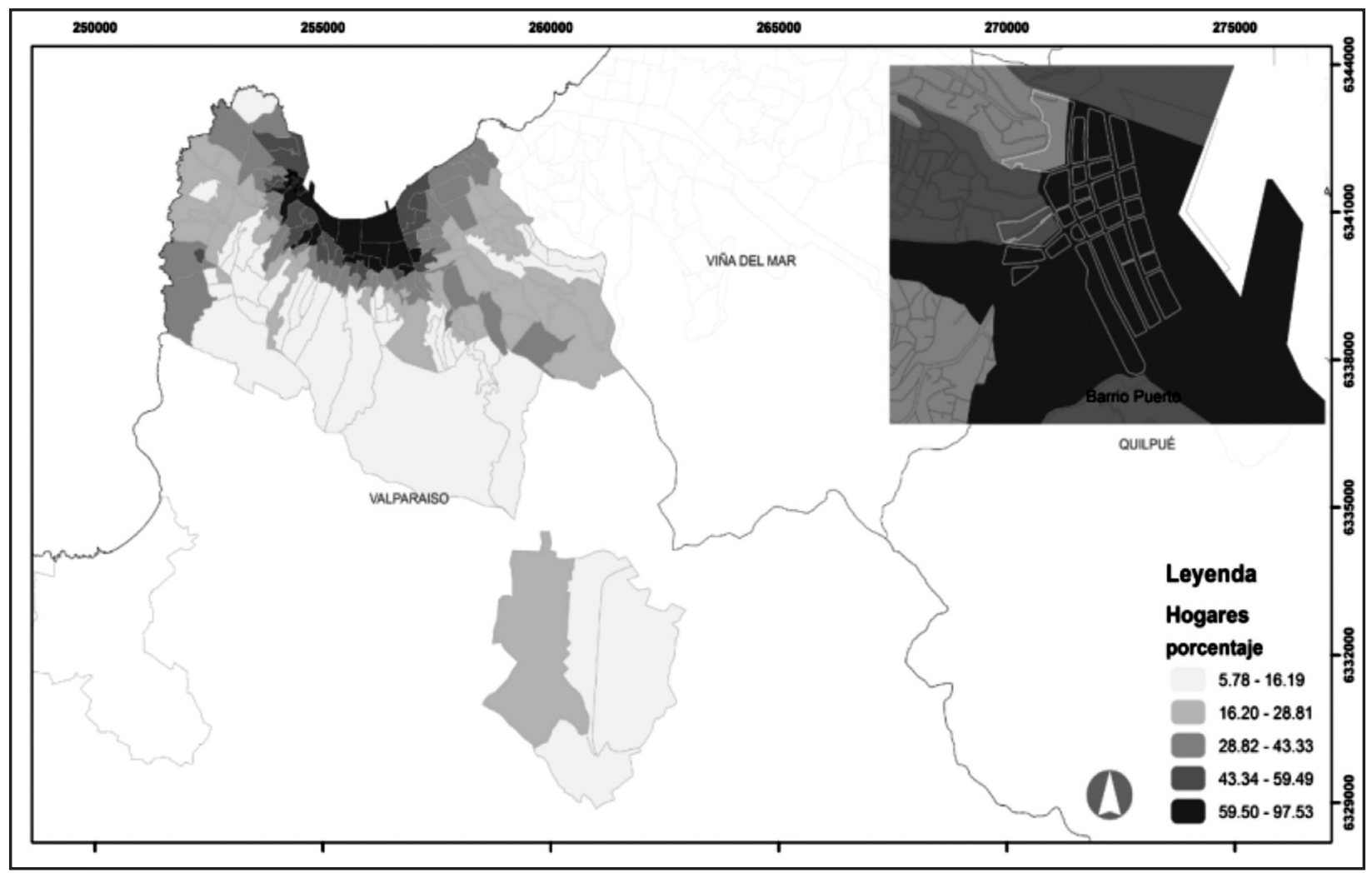

Fuente: Elaboración propia, 2015. 
El espacio público, de escala barrial, aparece muchas veces como el antídoto para los procesos de reificación urbana generados por el despoblamiento y las tendencias de expansión. En los orígenes de la sociología urbana, Simmel (2005) reivindica el espacio público y específicamente el espacio urbano, entendido como el lugar que da la posibilidad del encuentro con el otro. Así también, Wirth (2005) entiende la "heterogeneidad social" y el surgimiento de una "cultura urbana", como una de las características constitutivas de un modo de vida particularmente urbano. El barrio, la calle y el espacio público, se entienden como "el punto de contacto más accesible entre el espacio geométrico y el espacio social" (Greene, Link, Mora y Figueroa, 2014, p. 79), es decir, como el elemento que articula el espacio social con el espacio físico cuya estructura depende, en gran medida, de la estructura general de la ciudad (Lefebvre, 1969). Por otra parte para Mayol (1999), el barrio se erige en prácticas como el saludarse, caminar de determinada manera o conocerse unos a otros, en una relación de vecindad, que forja poco a poco una identidad común generadora de confianza y pertenencia. El barrio sería el resultado, entonces, de un imaginario colectivo, en el sentido que reúne las ideas de comunidad de los habitantes, operando así como vínculo entre el espacio privado del hogar y el espacio anónimo de la metrópolis. El barrio aparece también como el lugar donde el espacio es negociado, donde los diferentes grupos que lo habitan intentan, más o menos explícitamente, imponer sus valores y formas de vida (Gravano, 2005). En este sentido, el barrio se transforma en un elemento de socialización muy importante, donde se pueden construir vínculos sociales y donde se logra identificar las fronteras entre el nosotros y los otros (Gurvitch, 1953). Por lo tanto, es importante tener en cuenta estas aproximaciones, ya que se refieren a definiciones sobre la conformación social del espacio y la comunidad, entendidos como elementos constitutivos de una condición urbana que determina de alguna forma las posibilidades de inclusión y exclusión de sus habitantes, en un contexto donde los procesos estructurales de urbanización son desiguales y excluyentes.

Luego el barrio, a partir de sus múltiples definiciones, remite a una presunción de cierta cohesión social, a la sensación de pertenencia o familiaridad con relaciones sociales coincidentes en un espacio geográfico determinado. El barrio sería un lugar que es parte de una ruta diaria donde se recrea el registro de la vida, donde se puede tomar el transporte "de siempre", ir a lugares familiares (University of Chicago, 2014), etc., es decir, tener una experiencia de arraigo. Es lo que Zukin (2011) también denomina como autenticidad, en el sentido de aquel proceso continuo de vivir, trabajar, y construir diariamente la experiencia, bajo la expectativa de que el barrio de hoy, estará mañana. 
Particularmente la idea de arraigo, implica un anclaje, donde los sujetos tienden a fijarse, a generar estados de permanencia, estabilidad y reunión, que pueden estar basados en un carácter social, cultural e incluso espacial (Del Acebo, 1996). Es decir, el arraigo puede tener distintas motivaciones; por ejemplo, el arraigo de tipo social se entiende como aquella vinculación a grupos y organizaciones que involucran a personas afines sentimentalmente o políticamente. También existe un arraigo que puede ser de tipo cultural, vinculado a normas, modos de hacer o actuar, a comunidades, etnias, lazos sanguíneos, entre otros (Del Acebo, 1996); y por último el arraigo espacial que se vincula a la localización, que no implica necesariamente un vínculo estático con un lugar, sino que puede ser móvil y dinámico como sucede por ejemplo con aquellos que habitan la calle (Saucedo y Taracena, 2011). Así, la idea de arraigo, sin importar su naturaleza, tiene relación con una construcción sociocultural que propicia el amor a las pertenencias de los sujetos, las memorias compartidas, aunque el contexto sea precario o provisorio (Brito y Ganter, 2014). Por su parte, el arraigo tendría un estrecho vínculo con el concepto de barrio, pues influye en la relación entre el sujeto y el lugar de residencia, otorgando un sentimiento de comunidad y redes de protección: "[...] en el ejercicio cotidiano de recorrer el barrio y saludar a los vecinos [el arraigo] se reactualiza una y otra vez" (Márquez, 2014, p. 68). Es decir, el arraigo se trata de una construcción socio imaginaria de aquellas motivaciones subjetivas por las cuales un sujeto o un grupo social se establece, radica y relaciona con un lugar o con un grupo de pares.

Por otra parte, la idea de vulnerabilidad que aquí se propone, tiene que ver específicamente con su dimensión socio espacial (Soja, 2010), diferente a la sola dimensión social de la vulnerabilidad (Katzman, 2000), es decir, considera la pregunta por el espacio y su capacidad de promover procesos de exclusión, desigualdad y también accesibilidad (Roch, 2007). El término de vulnerabilidad en este sentido, ha tenido un desarrollo polisémico. Es así como se puede entender una condición de vulnerabilidad basada en la privatización de bienes urbanos de uso cotidiano (Cáceres, 2015); también se ha definido el concepto vinculado a ciertos sectores caracterizados por la falta de seguridad, delincuencia, carencias en la configuración física, que inciden en una baja calidad de vida, problemas sociales, pobreza endógena, entornos contaminados y obsolescencia de las estructuras urbanas (Kapstein y Aranda, 2014). Otras investigaciones hacen énfasis en la percepción de los propios habitantes y en la construcción de los medios de comunicación, que favorecen la estigmatización y estereotipación de los barrios (Margarit y Bijit, 2014).

Por nuestra parte, entenderemos "vulnerabilidad residencial" asociado a un hábitat urbano, como aquellas tensiones e incertidumbres sobre procesos 
de exclusión basados en la tenencia de una vivienda. En este caso, se trata de una situación intermedia, entre integración y desintegración a un sistema de relaciones urbanas, que otorga el arrendamiento en áreas centrales de una ciudad (Marín Toro, 2015).

En el caso del Barrio Puerto de Valparaíso, la vulnerabilidad residencial se hace patente en la incertidumbre respecto a las consecuencias que tendrá sobre los residentes una serie de proyectos que actualmente se encuentran en tramitación y en ejecución en el sector, provenientes tanto del ámbito público como privado y destinados al embellecimiento del barrio en el contexto de la nominación patrimonial, como se aprecia en figura 2 (Unesco, s.f.).

Se trata de políticas espaciales que apuntan a transformar este centro y donde ya se han realizado expulsiones de arrendatarios históricos (figura 3). Las nuevas expectativas derivadas de los posibles cambios espaciales, provocan en actores vinculados al sector -expertos, planificadores del ámbito público y privado, sociedad civil- una tendencia a querer modificar el paisaje material y humano de este lugar.
Se trata de un centro histórico atractivo en el que residen grupos de bajos ingresos en viviendas arrendadas, lo que constituye una fuente de conflicto. Siguiendo a Bourdieu (2001), los lugares son entendidos como espacios de lucha, especialmente cuando estos están cerca de bienes escasos y deseables. Destacando que la capacidad de dominar un espacio, ya sea material o simbólicamente, dependerá del capital poseído. Sin embargo, la falta de capital económico, social y cultural de los arrendatarios hace de ellos un grupo fácil de mover, poniendo en riesgo su proximidad física al centro urbano y la construcción socio imaginaria del lugar, que parece tener un valor en términos culturales para la propia definición del área central de Valparaíso como patrimonio de la humanidad. Por otra parte, las posibilidades de elegir una localización que cumpla con las mismas condiciones de accesibilidad a los servicios, como ocurre en el centro de las ciudades y que sea alcanzable en términos económicos para un grupo de bajos ingresos, se ven claramente reducidos en un eventual desplazamiento. 
FIGURA 2. PROYECTOS DE RENOVACIÓN URBANA Y ESTADO DE LOS PREDIOS EN EL BARRIO PUERTO

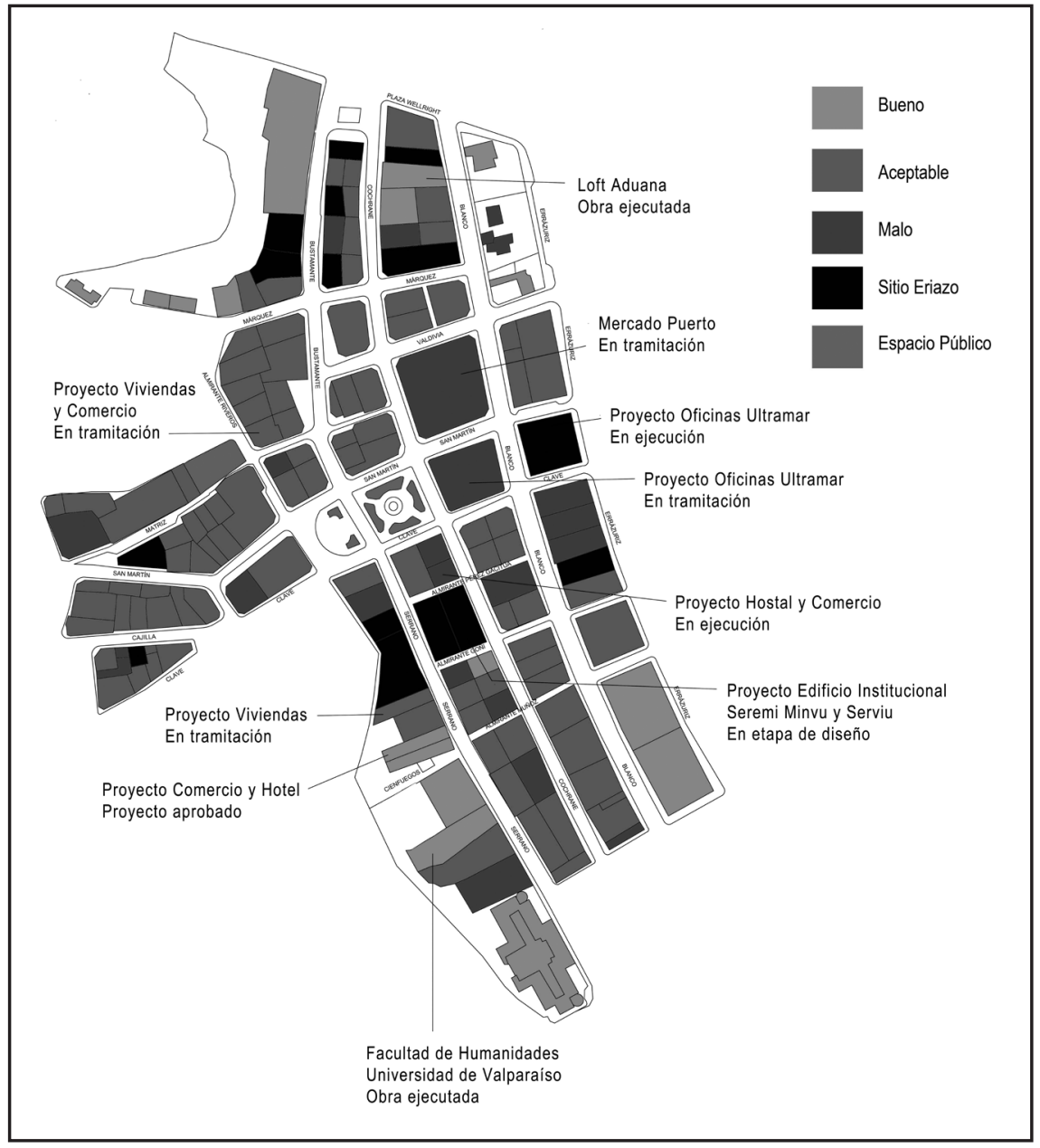

Fuente: Elaboración propia, 2015, en base a Zamora, 2013. 


\section{FIGURA 3. EXPULSIÓN DE ARRENDATARIOS EN EL BARRIO PUERTO ${ }^{6}$}

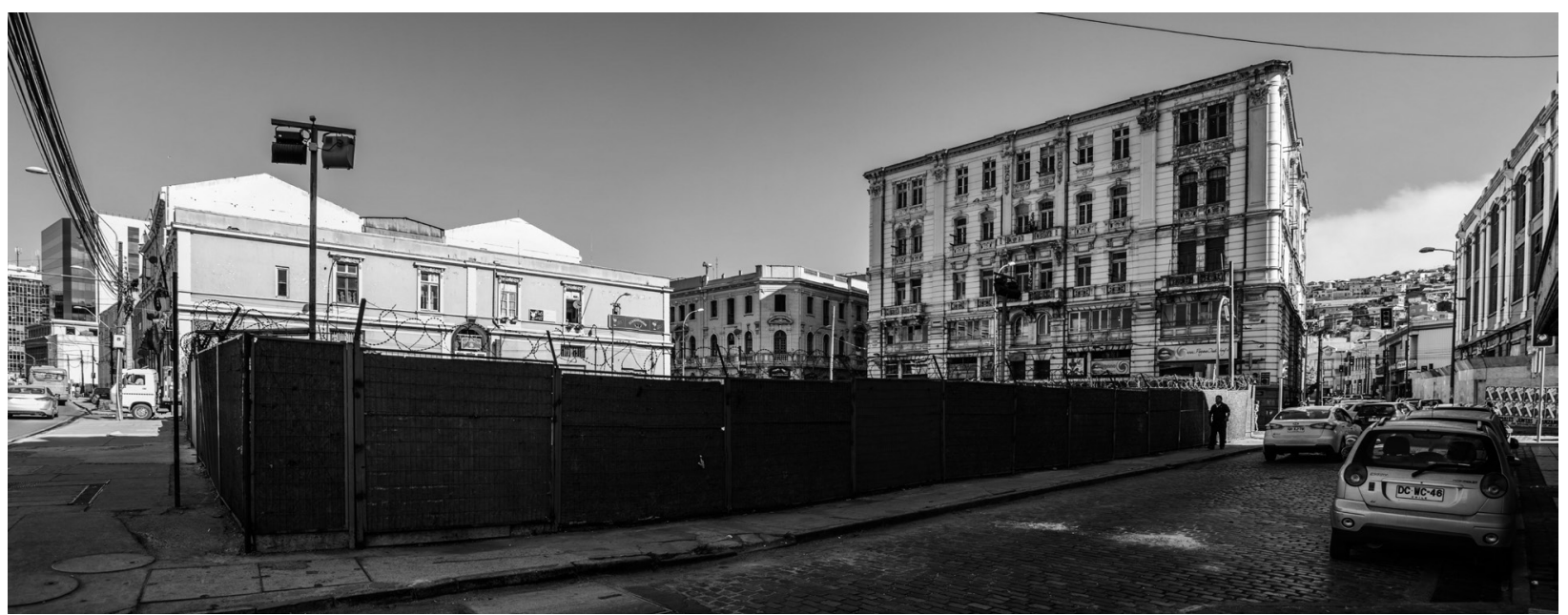

El arriendo, desde este punto de vista, es un modo de residencia que posee en sí mismo el riesgo de expulsión y exposición a diferentes amenazas, como son los procesos de renovación urbana, cambios en el uso del suelo, encarecimiento de la vivienda, entre otros.

$6 \quad$ En el fondo de la imagen el Edificio Astoreca, desalojado el año 2013 para su reconversión de arriendo de habitaciones a oficinas. En total fueron expulsadas 170 personas (Madariaga, 2013).

\section{Enfoque metodológico}

La estrategia metodológica se construyó a partir de un enfoque cualitativo (Taylor y Bogdan, 1987), con el objetivo de comprender una serie de dimensiones subjetivas importantes para caracterizar el fenómeno del arriendo y el arraigo en un contexto de vulnerabilidad residencial. Este enfoque metodológico involucra una aproximación dialéctica socioespacial que permite articular dos unidades 
que en sí mismas son dinámicas (Soja, 2010). En este sentido, se analizaron a través de datos de entrevistas, las siguientes dimensiones: motivaciones para arrendar; trayectoria del arriendo; perspectiva sobre la propiedad por parte de los arrendatarios; y posibles sentimientos de inseguridad vinculados a este tipo de tenencia.

Se define como unidad de análisis al hábitat residencial, configurado por un grupo humano particular y un espacio geográfico determinado: arrendatarios y el Barrio Puerto de la ciudad de Valparaíso.

Se realizó un muestreo intencionado de arrendatarios de bajos ingresos, considerados como informantes clave de los procesos descritos en el objeto de estudio. Se realizaron catorce entrevistas abiertas (Alonso, 1998), bajo el criterio de selección por accesibilidad y homogeneidad en su condición de arrendatarios, todos de bajos ingresos y residentes del Barrio Puerto. Ya que se trata de un grupo de difícil acceso, y sobre el que existe poca información estadística previa, no hubo una segmentación a priori respecto al sexo, edad o nivel de estudios, sino que los contactos se lograron a través de un proceso de "bola de nieve", a partir de un "portero", y el número de entrevistas se determinó a partir de un criterio de saturación de información (Valles, 1999). Los entrevistados fueron caracterizados a partir de su condición como residentes del barrio de acuerdo a la información entregada en las entrevistas, siendo agrupados como «residentes históricos» (ocho entrevistados) o "residentes nuevos" (seis entrevistados). El análisis de las entrevistas se realizó a través de un análisis de contenido simple, a partir del discurso codificado de las entrevistas. Este tipo de análisis se entiende, desde Krippendorf (1990, p. 28) como un "procedimiento destinado a formular, a partir de ciertos datos, inferencias reproducibles y válidas que puedan aplicarse a su contexto".

Finalmente, el análisis realizado es eminentemente interpretativo y responde al estudio en profundidad de un caso que, no obstante, pretende aportar elementos para comprender las dimensiones subjetivas del arriendo más allá de este caso particular.

\section{Características del arriendo de bajos ingresos en el Barrio Puerto de Valparaíso}

En general se encontraron dos tipos de arrendatarios de bajos ingresos presentes en el barrio: los históricos y los nuevos residentes. Los primeros se caracterizan por tener alrededor de 50 años y ocupación laboral variable entre trabajadores informales, esporádicos y cesantes. Se trata de los 
arrendatarios de habitaciones de casas antiguas, sin remodelaciones recientes y que han residido en el barrio y sus alrededores "toda la vida". A pesar de su historicidad y permanencia en el lugar se trata de los arrendatarios más invisibles del barrio, debido a que el arriendo y subarriendo de habitaciones se vincula al "conventillo", tipología de vivienda que carga con una fuerte connotación negativa relacionada a la marginalidad social, pobreza e insalubridad, estereotipo que recae tanto en las viviendas como en los moradores de ellas (Urbina, 2011).

En general se trata de edificaciones de dos o tres niveles, con un primer piso de uso comercial y los niveles superiores de uso residencial, donde el arriendo toma forma a través de la subdivisión por habitaciones y, aunque no fue generalizado en el caso de las entrevistas llevadas a cabo, el uso de un baño y cocina común (figura 4).

Así, el arriendo es una práctica prolongada en el barrio, que se ha dado por generaciones. Investigaciones históricas dan cuenta de esta característica desde finales del siglo XIX y principios del siglo $\mathrm{XX}$ vinculado al auge de la habitación popular económica (Urbina, 2011). Durante estos años el arriendo de habitaciones estaba estrechamente ligado a procesos de inmigración urbana en Valparaíso, como ha ocurrido en el siglo XXI en ciudades como Santiago y otras que concentran capital en el país (Márquez, 2014; Contreras, 2011). En estos casos, los procesos de migración no corresponden al movimiento del campo a la ciudad, sino más bien a una inmigración internacional. En los centros de estas ciudades la demanda por localización ha generado un mercado de arriendo para grupos de bajos ingresos caracterizado por el hacinamiento, cobros abusivos por las viviendas -e incluso el arriendo de camas-, con una mala calidad de la habitabilidad en general (Márquez, 2014). Por el contrario, en Valparaíso y el Barrio Puerto en particular, como se puede observar en la tabla 2, el cobro por el arriendo no parece excesivo, ni tampoco el hacinamiento es una de sus características principales. En la comuna de Valparaíso no existe un proceso de inmigración internacional relevante en términos cuantitativos y se encuentra un arriendo casi exclusivo de chilenos pertenecientes a grupos de bajos ingresos. 


\section{FIGURA 4. TIPOLOGÍA DE VIVIENDA DE LOS ARRENDATARIOS HISTÓRICOS}

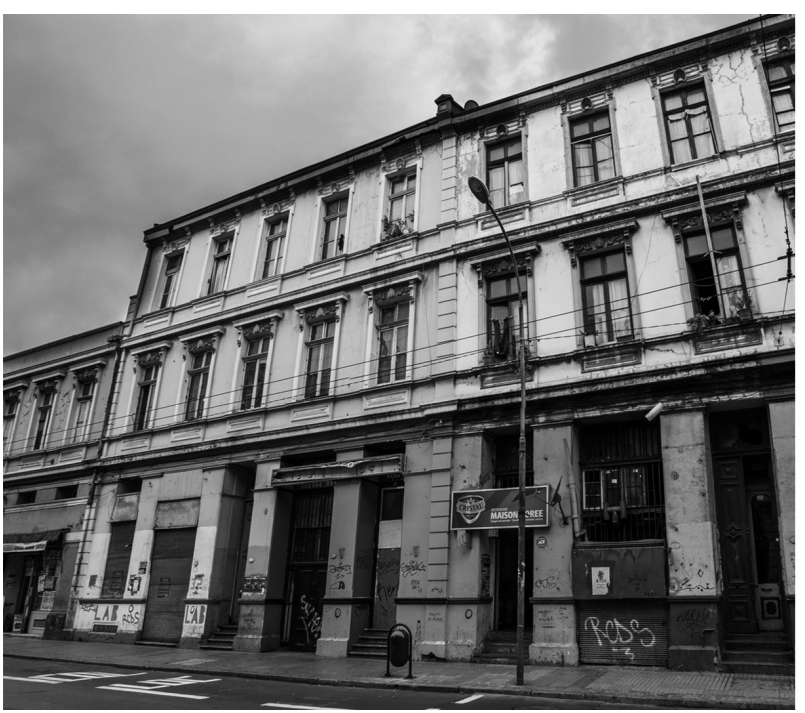

Fuente: Autor, 2014.

En el segundo grupo de entrevistas están los arrendatarios nuevos, quienes declaran un tiempo acotado de residencia en el barrio y con la expectativa futura, aunque no certera, de vivir en alguna otra etapa de la vida en una vivienda propia. En su mayoría, se trata de jóvenes o adultos-jóvenes pertenecientes a una "burguesía informal" (Davis, 2007). Es decir, personas relacionadas al sector comercial o de servicios y profesionales por cuenta propia que no han podido acceder a las capas formales del mercado de trabajo (tabla 3).

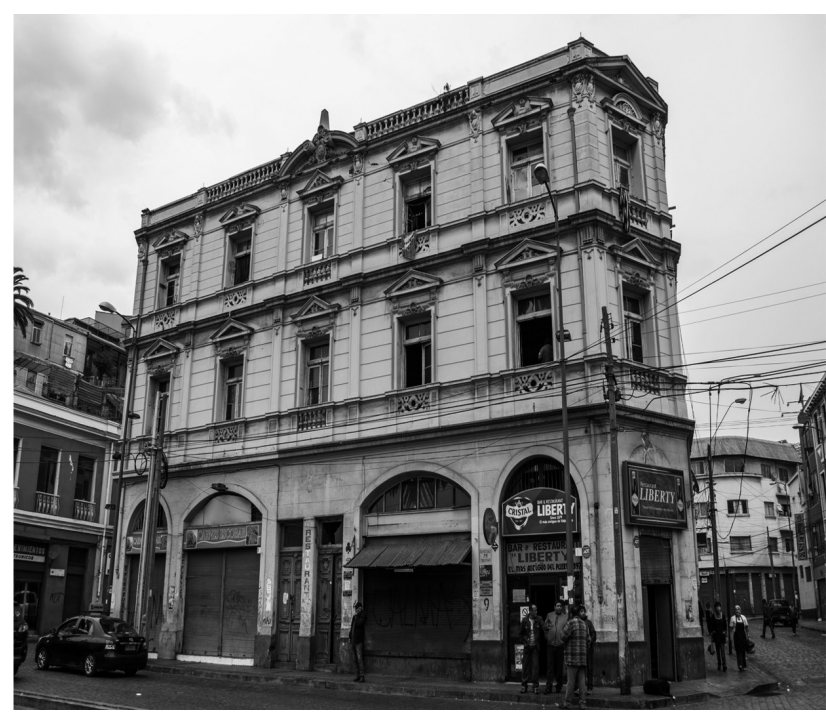

Se trata de arrendatarios de habitaciones remodeladas y/o departamentos compartidos (ver figura 5), vinculados laboralmente a lo que se conoce como industria creativa: diseñadores, arquitectos, músicos, y parte del mundo de las artes en general, pero que lo hacen desde la informalidad, la flexibilidad y precariedad laboral, con sueldos variables, por lo que arrendar en el Barrio Puerto les permite tener una vida cómoda a bajo costo. 
TABLA 2. RESUMEN DE LAS CARACTERÍSTICAS DE LOS ARRENDATARIOS HISTÓRICOS ENTREVISTADOS

\begin{tabular}{|c|c|c|c|c|c|c|c|}
\hline Caso & $\begin{array}{l}\text { Edad } \\
\text { en } \\
\text { años }\end{array}$ & Ocupación & $\begin{array}{c}\text { Valor actual } \\
\text { del arriendo } \\
\text { en miles \$ } \\
\text { chilenos }\end{array}$ & Tipo de vivienda & $\begin{array}{c}\mathrm{N}^{\circ} \text { de residentes } \\
\text { en la casa del } \\
\text { entrevistado/a }\end{array}$ & $\begin{array}{l}\text { Años en } \\
\text { la actual } \\
\text { vivienda }\end{array}$ & $\begin{array}{l}\text { Años residiendo en } \\
\text { el Barrio Puerto o } \\
\text { en sus alrededores }\end{array}$ \\
\hline 1 & 50 & Asesora de hogar & 100 & $\begin{array}{l}\text { Departamento, dos habitacio- } \\
\text { nes, baño y cocina privada. En } \\
\text { edificio antiguo }\end{array}$ & 3 & 5 & Toda la vida \\
\hline 2 & 60 & $\begin{array}{l}\text { Cuidadora de } \\
\text { autos }\end{array}$ & 68 & $\begin{array}{l}\text { Casa dos habitaciones, baño } \\
\text { y cocina privada. En casona } \\
\text { antigua }\end{array}$ & 2 & 7 & Toda la vida \\
\hline 3 & 53 & $\begin{array}{l}\text { Subarrienda } \\
\text { habitaciones }\end{array}$ & $450^{*}$ & $\begin{array}{l}\text { Casona antigua, más de } 10 \\
\text { habitaciones }\end{array}$ & 8 & 4 & 20 \\
\hline 4 & 59 & Dueña de casa & 50 & $\begin{array}{l}\text { Tres habitaciones, bañoy } \\
\text { cocina compartida. En casona } \\
\text { antigua }\end{array}$ & 3 & 20 & Toda la vida \\
\hline 5 & 53 & Asesora de hogar & 50 & $\begin{array}{l}\text { Casa de tres habitaciones, baño } \\
\text { y cocina privada. En casona } \\
\text { antigua }\end{array}$ & 2 & 2 & Toda la vida \\
\hline 6 & 54 & $\begin{array}{l}\text { Vende pescados, } \\
\text { hace aseo y cuida } \\
\text { autos }\end{array}$ & 70 & $\begin{array}{l}\text { Una habitación, baño y cocina } \\
\text { compartida. En casona antigua }\end{array}$ & 1 & 13 & Toda la vida \\
\hline 7 & 56 & Cesante & 70 & $\begin{array}{l}\text { Una habitación, baño comparti- } \\
\text { do. En casona antigua }\end{array}$ & 1 & 1 & Toda la vida \\
\hline 8 & 49 & $\begin{array}{l}\text { Subarrienda } \\
\text { habitaciones }\end{array}$ & $400^{*}$ & $\begin{array}{l}\text { Casona antigua, más de } 10 \\
\text { habitaciones }\end{array}$ & 7 & 29 & 29 \\
\hline
\end{tabular}

* Corresponde al valor total de una casona, subarrendada por piezas.

Fuente: Elaboración propia en base a las entrevistas realizadas, 2015. 


\section{TABLA 3. RESUMEN DE LAS CARACTERÍSTICAS DE LOS ARRENDATARIOS NUEVOS ENTREVISTADOS}

\begin{tabular}{|c|c|c|c|c|c|c|c|}
\hline Caso & $\begin{array}{l}\text { Edad } \\
\text { en } \\
\text { años }\end{array}$ & Ocupación & $\begin{array}{l}\text { Valor } \\
\text { actual del } \\
\text { arriendo } \\
\text { en miles } \$ \\
\text { chilenos }\end{array}$ & Tipo de vivienda & $\begin{array}{l}N^{\circ} \text { de habitantes } \\
\text { en la casa del } \\
\text { entrevistado/a }\end{array}$ & $\begin{array}{l}\text { Años en } \\
\text { la actual } \\
\text { vivienda }\end{array}$ & $\begin{array}{l}\text { Comuna } \\
\text { anterior de } \\
\text { residencia }\end{array}$ \\
\hline 9 & 26 & Músico & 155 & $\begin{array}{l}\text { Departamento, } 5 \text { ha- } \\
\text { bitaciones. Edificio } \\
\text { antiguo }\end{array}$ & 6 & 2 & Viña del Mar \\
\hline 10 & 23 & $\begin{array}{l}\text { Parvularia y atiende } \\
\text { una galería de arte }\end{array}$ & 165 & $\begin{array}{l}\text { Departamento, } 4 \text { ha- } \\
\text { bitaciones. Edificio } \\
\text { antiguo }\end{array}$ & 3 & 1 & Vitacura \\
\hline 11 & 34 & $\begin{array}{l}\text { Arquitecto free } \\
\text { lance }\end{array}$ & 180 & $\begin{array}{l}\text { Departamento, } 4 \text { ha- } \\
\text { bitaciones. En edificio } \\
\text { antiguo }\end{array}$ & 5 & 4 & Viña del Mar \\
\hline 12 & 36 & $\begin{array}{l}\text { Coordinador de } \\
\text { eventos deportivos }\end{array}$ & 100 & $\begin{array}{l}\text { Habitación remodelada } \\
\text { en edificio antiguo }\end{array}$ & 1 & 1 & Viña del Mar \\
\hline 13 & 36 & $\begin{array}{l}\text { Estudiante y garzón } \\
\text { en el Congreso } \\
\text { Nacional }\end{array}$ & 200 & $\begin{array}{l}\text { Departamento, } 2 \text { ha- } \\
\text { bitaciones. Edificio } \\
\text { antiguo }\end{array}$ & 3 & 1 & Cabildo \\
\hline 14 & $57^{*}$ & Dueña de casa & 350 & $\begin{array}{l}\text { Departamento, } 3 \text { ha- } \\
\text { bitaciones. Edificio } \\
\text { antiguo }\end{array}$ & 4 & 0 & Valparaíso \\
\hline
\end{tabular}

* Se trata del caso de un beneficiario al subsidio de arrendamiento otorgado exclusivamente en Valparaíso a propósito del mega incendio ocurrido en el mes de abril del año 2014

Fuente: Elaboración propia en base a las entrevistas realizadas, 2015. 


\section{FIGURA 5. TIPOLOGÍA DE VIVIENDA DE LOS ARRENDATARIOS NUEVOS}
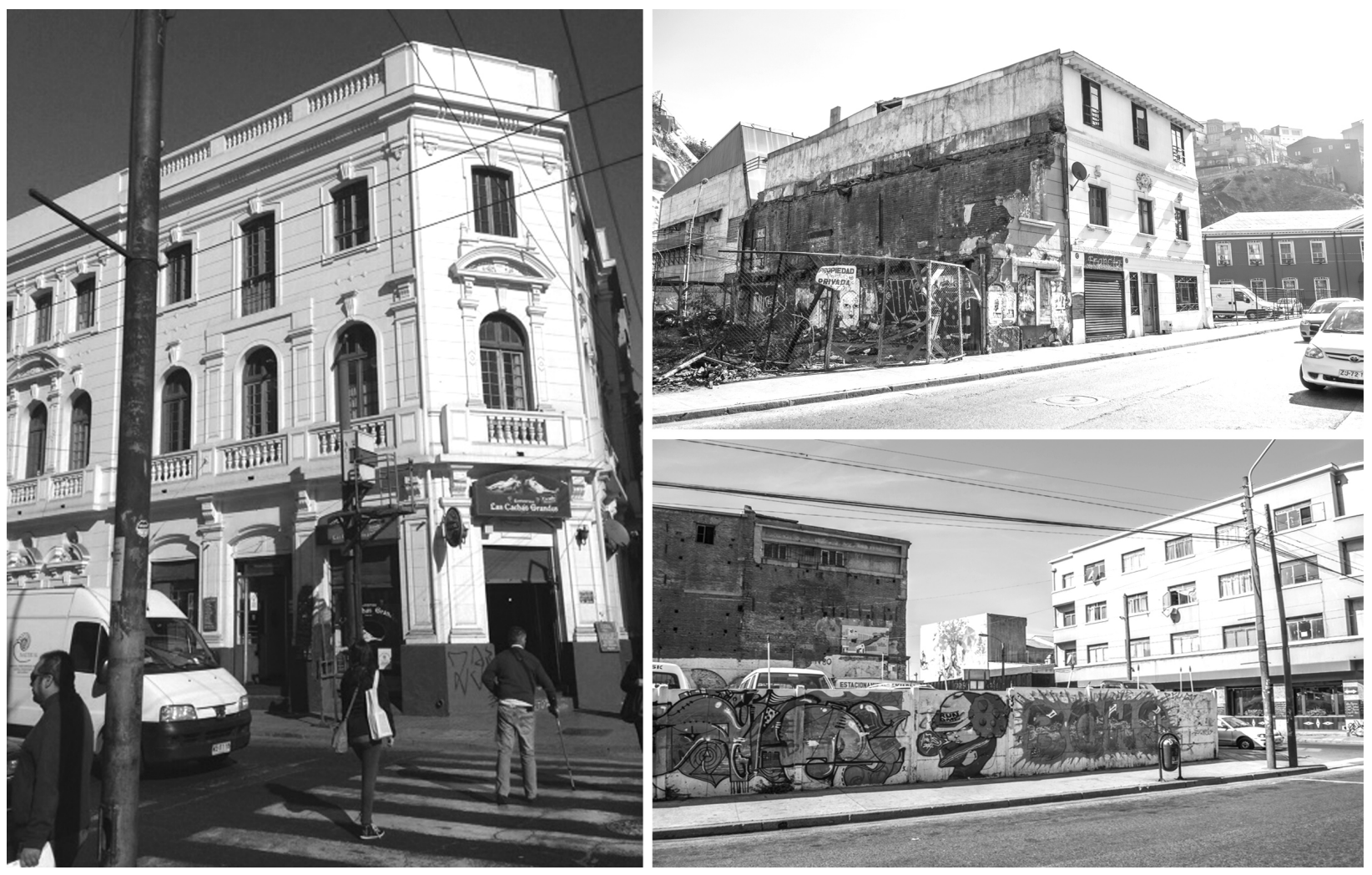

Entre sitios eriazos y edificaciones abandonadas existen edificios remodelados o antiguos departamentos que son ocupados por los arrendatarios que hemos identificado como nuevos. Fuente: Autor, 2014-2015. 


\section{Vulnerabilidad residencial}

"ese es el problema de arrendar po", que estás ahí, a disposición de lo que el dueño te diga" (Hombre, 34 años, arrendatario nuevo, 2014)

En Chile, mantener o no un estado de arrendamiento depende casi exclusivamente del dueño del inmueble, quien de forma directa puede pedir formal o informalmente el desalojo a los arrendatarios. O bien, utilizar otras estrategias como el aumento del valor del arriendo, para así presionar a la expulsión:

"fue bien triste porque ese día se casaba mi hija y teníamos todos los preparativos y estábamos todos listos, nos fuimos a la fiesta, y el dueño de casa, no sé por qué motivo, razón o circunstancia, cuando llegamos de la fiesta en la madrugada, había cerrado las puertas y las ventanas con latas y no podíamos entrar, y mi yerno vivía en el mismo pasaje en una casa del frente y tuvimos que pasar ahí la noche en la casa de mis consuegros, tuvimos que estar ahi hasta que el caballero se animara a abrirnos la puerta y no había caso, tuvimos que llamar a la comisaría $y$ vino una pareja de carabineros y lo obligó a que nos abriera la puerta porque se estaba apoderando de cosas que no eran de él, todo lo que teníamos adentro era de nosotros.
Entrevistador: ¿y ustedes estaban a tiempo con el pago del arriendo?

Sí, estábamos bien con el arriendo, lo que pasa es que el caballero era de un carácter difícil y de repente uno lo veía...era buena persona lo invitábamos a almorzar y otras veces andaba enojado" (Mujer, 59 años, arrendataria histórica, 2014).

El arriendo para grupos de bajos ingresos tanto de habitaciones como de departamentos compartidos, posee un sistema de funcionamiento legítimo entre privados con las características que esto implica: pagos de mes de garantía, contratos de arrendamiento, presencia de corredoras de propiedades que se hacen cargo del cobro mensual de las habitaciones o departamentos. A pesar de la consolidación del sistema de arriendo en este barrio, existe un área en la que ni propietarios ni arrendatarios se han hecho cargo: la mantención de las viviendas.

En este sentido, las casas debido a su antigüedad y uso intensivo, en especial en aquellas de habitaciones subdivididas, presentan deterioros cuyas reparaciones significan un desembolso económico importante que los arrendatarios no quieren asumir, contribuyendo al desgastado ambiente material, al aspecto físico abandonado y descuidado del Barrio Puerto. Esto se observa en trizaduras de murallas, estucos de cemento desprendido, además de filtraciones de agua y humedad (ver figura 6). 
"[El departamento] tiene una destrucción porque es antiguo, por ejemplo en mi pieza hay un closet que da con la ducha y se está humedeciendo el piso por debajo y no sé qué hacer con eso. No tengo plata para invertir, porque es un gasto importante igual arreglar el piso, también pienso, claro, no es mi casa [risas] estoy complicado con ese tema" (Hombre, 34 años, arrendatario nuevo, 2014).

"ahí cayó todo el techo, se cayó todo, mi marido llegó y arregló [...] vinieron a vernos de la municipalidad y esta casa "se sentó", con el temblor del otro día, y yo fui a hablar con el corredor y le dije que le dijera al dueño que tiene que levantar la casa y poner unos pilares, si es posible unos pilares anchos porque o si no la casa se va a volver a caer, yo le he dicho al dueño y nunca ha hecho nada, al final no son los arrendatarios, son los dueños que no quieren hacer nada" (Mujer, 50 años, arrendataria histórica, 2014).

Otra de las características de la vulnerabilidad residencial es la venta de casas en el barrio, en el contexto de los continuos procesos de abandono y gentrificación (Marcuse, 1985) que actualmente caracteriza este lugar (ver figura 7). La conjunción de ambos procesos tiende a mermar la oferta de arriendo económico, pues ninguno de ellos reemplaza o mejora la oferta existente actualmente, y solo implica una reducción de la forma de habitación tradicional.
La inyección de capital vuelve cada vez más atractivo a este sector y por lo tanto más caro, de manera que los propietarios de los inmuebles disponen de alternativas más atractivas en términos de capitalización respecto a la opción de continuar arrendando a grupos de bajos ingresos. En este sentido, al no existir incentivos públicos ni privados para mantener la oferta de arriendo, lo más probable es que esta oferta termine en el algún momento por desaparecer en el barrio. 
FIGURA 6. PROBLEMAS INHERENTES A LA VIVIENDA ANTIGUA EN EL BARRIO PUERTO: CONSTRUCCIÓN EN ADOBILLO
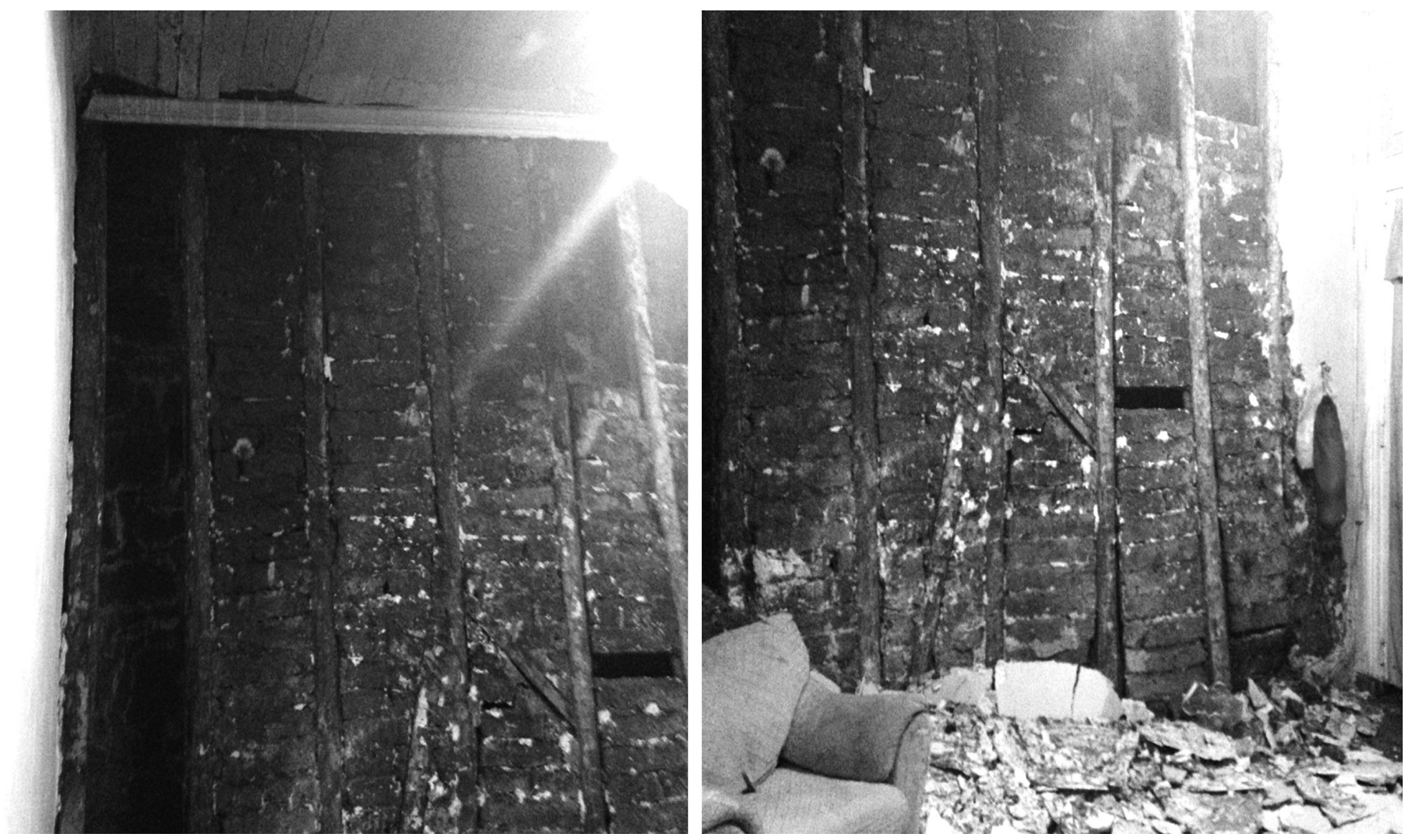

Las imágenes corresponden a una de las habitaciones de un arrendatario histórico entrevistado. Se desprende la muralla debido a un problema de filtración de agua proveniente de la vivienda que está ubicada en la planta superior. Esta habitación fue clausurada, pero sin ninguna solución por parte del propietario de la casa al finalizar esta investigación. Fuente: Autor, 2015. 


\section{FIGURA 7. PROCESOS DE ABANDONO Y GENTRIFICACIÓN EN EL BARRIO PUERTO DE VALPARAÍSO}
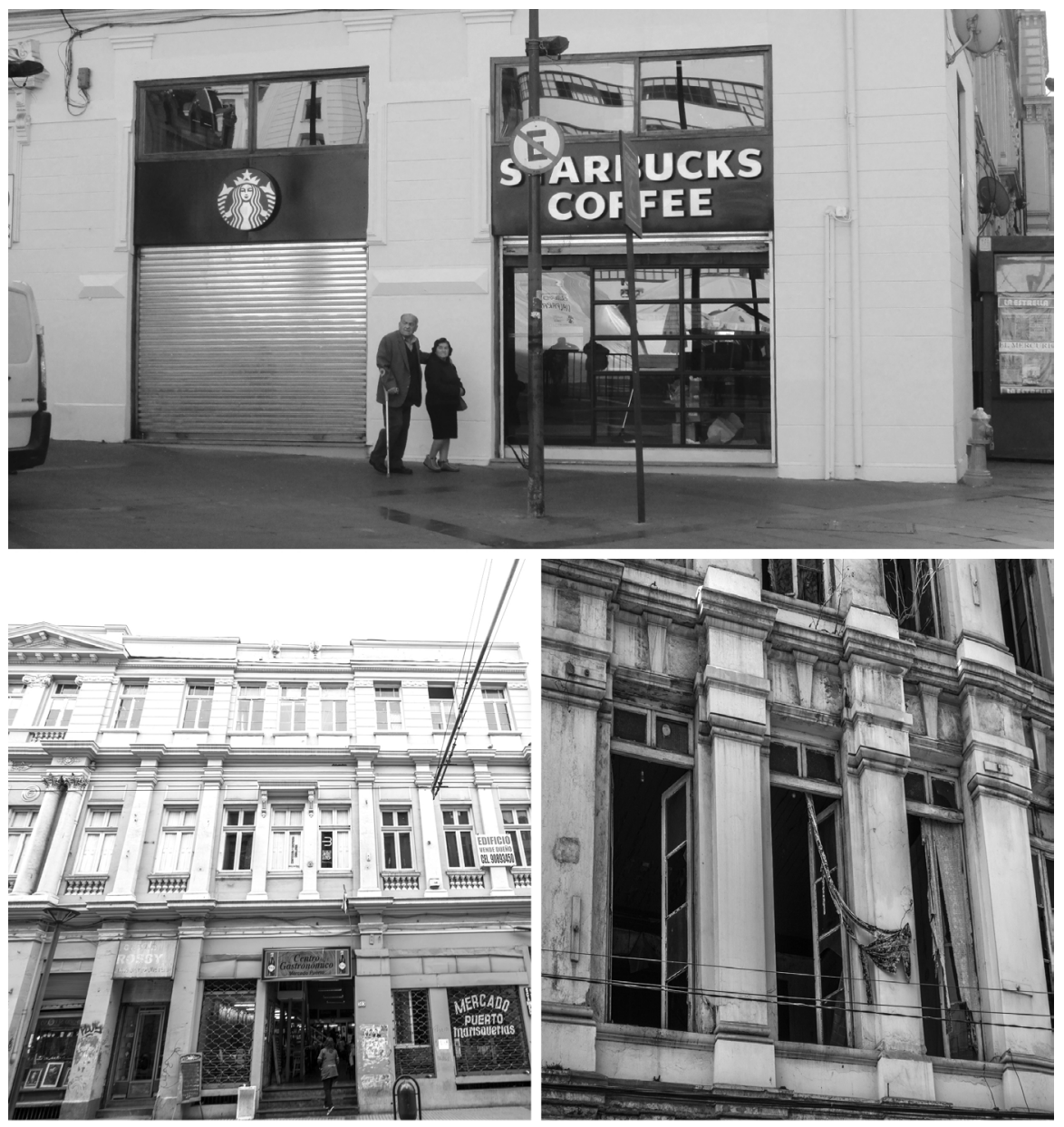

En la primera imagen superior el café Starbucks abierto el año 2015. La imagen inferior izquierda se observa la venta de un gran inmueble de uso comercial, y al costado derecho tipologías de viviendas claramente en abandono en el Barrio Puerto Fuente: Autor, 2014-2015. 
La condición patrimonial del sector ha generado inversiones públicas vinculadas a un embellecimiento del barrio, como la reposición de adoquines, mantención de las fachadas y nuevo alumbrado, pero aún sin vincularse a los problemas particulares de los sitios eriazos o de las viviendas antiguas, como la carencia de cortafuego, falta de mantenimiento de instalaciones eléctricas, de gas, y de la construcción predominante en adobillo ${ }^{7}$, entre otras. Se trata de problemas estructurales, que necesitan de inversiones de largo plazo e incluso de un gasto más intensivo de recursos necesarios para asegurar la vida útil del barrio.

En resumen, a partir del análisis de las entrevistas con arrendatarios del Barrio Puerto, la vulnerabilidad residencial identificada para este caso estaría compuesta de a lo menos cinco dimensiones:

- Dimensión ideológica o ethos de la propiedad privada de la vivienda: Los arrendatarios son un grupo invisible en el contexto urbano, que no ha sido asimilado por las políticas de gobierno a través de sus programas de vivienda. Falta de reconocimiento social que se reproduce en distintas escalas, desde la vida cotidiana hasta el nivel nacional e incluso latinoamericano (Blanco et al., 2014).

7 Técnica constructiva mixta, de estructura de madera con ladrillos de tierra utilizados como relleno.
- Dimensión de poder: los arrendatarios son un grupo urbano carente de poder, es decir, incapaz de demandar mejoras respecto a la calidad de sus hogares. Incluso una acción en este sentido podría ser un aliciente para aumentar el valor del arriendo; tampoco tienen derecho a indemnizaciones o realojamientos luego de sucedido un desplazamiento involuntario; no son un grupo organizado que genere una presión para protegerse a sí mismos.

- Dimensión espacial: Frente a procesos de renovación urbana los arrendatarios están propensos al desplazamiento, especialmente de aquellos sectores más atractivos de la ciudad debido a la inseguridad con la tenencia de la vivienda; susceptibles a cambios debido a un aumento en el precio o cambios de uso de suelo. Además, al no existir incentivos para la generación de nueva oferta de vivienda para este sector, tanto pública como privada, se produce un mercado habitacional que está forzado a desaparecer.

- Dimensión económica: en el caso de los arrendatarios de bajos ingresos, las fluctuaciones en los valores de la renta repercuten inmediatamente en las posibilidades de permanencia de los arrendatarios. Existe también la dificultad para ahorrar y acceder a una alternativa a la tenencia de arriendo, que no implique sacrificar localización. 
- Dimensión de infraestructura: La actual oferta de vivienda para arriendo en este barrio corresponde a viviendas antiguas, sin mantención de ningún tipo, por lo que su destrucción y posibles perjuicios a los moradores constituyen una posibilidad latente.

\section{Arraigo espacial}

"siempre en arriendo, desde que nací, siempre en arriendo"

(Mujer, 53 años, arrendataria histórica)

Resulta paradojal que paralelamente a las inseguridades propias de arrendar, este tipo de tenencia de la vivienda provea condiciones que motivan su permanencia. Esto se produce porque existe una identificación con el lugar, construida a través de la relación de un sujeto con el espacio, una fijación fundamentalmente cualitativa. El tipo de arraigo que nos interesa en este contexto, es el de tipo espacial, porque es donde encontramos el vínculo entre arrendatarios y el Barrio Puerto, pues es un arraigo vinculado estrechamente a la localización.

El lugar, entendido desde Lefebvre (1969) al mismo tiempo como un espacio territorial, social, político y cultural, que permite la realización práctico-sensible del sujeto, estaría en riesgo por el desplazamiento, y por lo tanto, por el desarraigo y empobrecimiento vecinal y de la vida en general del barrio. Lo urbano en un sentido amplio y desde este punto de vista, es comprendido como una forma de encuentro y de conexión con la vida social.

Lo que existe en el caso estudiado es un arraigo de los arrendatarios al lugar, tanto en su localización como en su condición de generador de sentido, ya que el Barrio Puerto ofrece centralidad urbana en términos amplios. Para los arrendatarios de bajos ingresos, vivir en el centro reporta una oportunidad territorial y económica. La localización, que permite accesibilidad y movilidad, posibilita el contacto con otras escalas, más allá de la vivienda, es decir, del barrio a la ciudad. Se trata de usos que además del residencial, convocan a la recreación, a actividades económicas, de educación, salud, entre otras.

El Plan es un lugar privilegiado para residir en la particular morfología de la ciudad de Valparaíso; el Barrio Puerto está cercano a zonas comerciales y servicios públicos, la conectividad permite el ahorro en locomoción y la posibilidad de generar redes laborales cercanas, primordial para los grupos de bajos ingresos. Resulta evidente cómo el atributo de la localización puede ser incluso más importante que la propiedad de una casa o la calidad de una vivienda. 
"A mí me tocó una casa para Placilla la otra vez por el SERVIU y yo le dije que no [...] la rechacé, claro que me arrepiento, aunque no tanto porque me gusta acá [...] yo prefiero arrendar aquí, es que mire, la plata de la micro, para trabajar por ejemplo, yo me voy a la pega y le digo illéveme por \$200? y me llevan po', y los choferes a una hasta la conocen y [te dicen] sí, sube, sube no más". (Mujer, 50 años, arrendataria histórica, 2014).

"como te decía esta casa es súper helada, no tengo ventanas, no entra la luz, pero nosotros no nos hemos movido de aquí porque pagamos poco, porque fijate que para una pieza están pidiendo de 80 mil pesos para arriba, ipor una pieza!, y yo aquí pago 50 mil por tres piezas, el baño y la cocina". (Mujer, 59 años, arrendataria histórica, 2014).

Más allá de una estrategia de tipo instrumental del arrendamiento en el centro, hay que recordar que se trata de un barrio, donde la vivienda, independiente de su condición de propiedad, ha permitido la generación de una vida social adecuada para promover vínculos significativos. Lazos que se originan en el compartir cotidiano, en la "vida de barrio" y en la movilidad que permite la localización.

La ausencia de un vínculo de propiedad con una vivienda o el carácter móvil del arriendo, no implican sentimientos de desarraigo con la casa y el entorno. El hogar desde el punto de vista de un

8 Sector ubicado en la comuna de Valparaíso, que se encuentra a $100 \mathrm{~km}$ de Santiago y $11 \mathrm{~km}$ del plan de la ciudad de Valparaíso, que ha experimentado un rápido crecimiento poblacional. proyecto social duradero, si bien remite a la morada material, al mismo tiempo implica vínculos afectivos a un patrimonio de bienes simbólicos (Bourdieu, 2001), esto es, memorias compartidas, prácticas, pertenencias, incluso si la vivienda arrendada tiene un contexto precario, y en ocasiones, provisorio (Brito y Ganter, 2014). Especialmente en el caso de los arrendatarios históricos, quienes han residido en una misma casa por veinte o treinta años aproximadamente, o en el barrio y sus alrededores en similar cantidad de años, es posible observar un vínculo con el hogar, aunque esta sea una habitación o un conjunto de ellas, debido a la estabilidad residencial que se ha generado en este sector. Los sujetos entrevistados mencionan el lugar donde viven como "mi casa", cuestión que remite a sentimientos de pertenencia vinculados a relaciones sociales que la vivienda permite generar, más allá de la propiedad o de un arraigo económico.

"se lo he dicho a los dueños y se ríen, porque una vez que vinieron para acá, habia un problema en el techo y vinieron y yo les decía: 'esta es mi casa', y me dijo sí po', si tú acá pagas arriendo, pagas por vivir acá y es tu casa, y sí pó. Si me casé, tuve a mis hijos, los crié, entonces yo siempre lo he dicho, que esta es mi casa". (Mujer, 49 años, arrendataria histórica, 2014). 
En el caso de los arrendatarios nuevos, también es posible encontrar un arraigo originado en la "vida de barrio", que contiene una forma particular de vivir y habitar un espacio:

"Lo sentimos como nuestro hogar, un departamento amable y un barrio amable, entonces como que uno agarra cariño" (Hombre, 34 años, arrendatario nuevo, 2014).

En el caso estudiado, el arraigo espacial se define en relación con la localización, la vida de barrio y el arriendo económico que aquí existe. Tiene la particular característica de ser móvil y dinámico (Saucedo y Taracena, 2011), es decir, la casa puede cambiar, pero no el barrio. En el Barrio Puerto se pasó del sueño de la casa propia, al arriendo en propiedad. Aunque la propiedad de la vivienda está incrustada como un sistema de creencias y de valores, un ethos y visión moral del mundo (Bourdieu, 2001), pero ya sea por la incapacidad de generar ahorros o por no cumplir con los requisitos para un subsidio habitacional, el arriendo en este barrio pasó de ser un síntoma de la imposibilidad de un sueño, a una forma de vida.

Entrevistador: ¿Y ustedes tienen, junto a su esposo, el sueño de la casa propia?

¿Quién no? Dime quién no.

Entrevistador: ¿Pero no les apura?

No, y no me caliento la cabeza por eso. No, cuando los niños estaban chicos, sí me calentaba mucho la cabeza porque eran muchos, eran 4, pero después vi que mis cabros empezaron a crecer, empezaron a irse, ya no me quita el sueño como antes". (Mujer, 49 años, arrendataria histórica, 2014).

El conocimiento de este grupo permite señalar que la propiedad de una vivienda como fin último, es una construcción social y que existen también otros sujetos dispuestos al arrendamiento como modo permanente de tenencia de la vivienda. Aunque los arrendatarios no gozan de la seguridad de la permanencia como los propietarios, se puede afirmar que el arriendo barato es particularmente útil para aquellos con ciertas características sociodemográficas de vulnerabilidad como núcleos unifamiliares, adultos mayores, hogares de jefatura femenina, así como también para los grupos económicamente vulnerables en general, pues permite disfrutar de las ventajas de la vida urbana como espacio social vivido y de convivencia, a través de la apropiación y construcción de lugar.

\section{Conclusiones}

La primacía de la propiedad privada como ideología en el país y América Latina en general, ha invisibilizado al arriendo como un objeto de investigación en los estudios urbanos y también al arrendatario como un sujeto de política pública. A 
lo largo de este artículo -estudiando el caso específico del Barrio Puerto en Valparaíso-, se ha buscado relevar la condición de arrendatario, analizando de qué forma el arraigo también está presente en este tipo de habitantes de la ciudad, y cómo su situación se ve constantemente amenazada por el nivel de vulnerabilidad residencial al que tienden a estar expuestos.

El caso del arriendo para grupos de bajos ingresos, se presenta como una forma de habitar que necesita de una respuesta política. Situados en un área de denominación patrimonial, el reconocimiento del arriendo posibilita el rescate del patrimonio sin clichés, es decir, considerar a quienes habitan en los espacios territoriales valorados. En el caso del Barrio Puerto se trata de personas de bajos ingresos, a quienes de esta forma se les proporciona la oportunidad de seguir ocupando una parte de la ciudad que ofrece buena localización, conectividad, oferta de servicios educacionales, de salud, empleo, recreación, como también memoria, pertenencia y vida de barrio.

Entonces, ¿no es acaso el arriendo, como forma de habitar, una peculiaridad más que define la condición patrimonial del Barrio Puerto, dada su larga historicidad? El análisis de las entrevistas realizadas permitió mostrar de qué manera el arraigo al lugar no está necesariamente vinculado a la propiedad, y cómo las características de localización juegan un papel fundamental en la valoración subjetiva del lugar de residencia. De esta forma, arraigo y condición de arrendatario se combinan de forma particular en el contexto de un barrio central, lo que permite fundamentar la relevancia de estas formas de habitar la ciudad desde una perspectiva de política pública. Al mismo tiempo, frente a los procesos de renovación urbana descritos, asegurar la oferta de arriendo barato permite mantener una de las características de los barrios centrales: su heterogeneidad social.

Por otro lado, el caso representa un barrio céntrico e histórico, un área fundacional, consolidada y de vocación residencial (Inzulza y Galleguillos, 2014) que ha experimentado una inyección de capital a secas, más que nueva infraestructura o un mercado inmobiliario visible (López Morales, 2013), y donde ya se registraron desplazamientos de arrendatarios históricos. De esta manera Valparaíso y el Barrio Puerto en particular, poseen características que les diferencia de Santiago al analizar el fenómeno de la gentrificación (Inzulza, 2012; Inzulza y Galleguillos, 2014; López Morales, 2013; López Morales, Arriagada, Gasic y Meza, 2015). Debido a su condición patrimonial, en Valparaíso existen normativas para la preservación del paisaje arquitectónico, por tanto condominios cerrados o proyectos de densificación en altura no son los protagonistas de la reestructuración habitacional. Lo que existiría es un reingreso de capital (Smith, 2012) más amplio que la sola llegada de nuevos residentes, configurando las particulares condiciones 
de vulnerabilidad residencial que caracterizan a los arrendatarios de este barrio, marcadas por la posibilidad latente del desplazamiento y la falta de poder para enfrentar estas amenazas, así como también por la exposición a riesgos derivados de la precariedad material de la construcción.

Para finalizar, este artículo da cuenta, a partir de una aproximación descriptiva y cualitativa, de las particularidades de los arrendatarios y de los beneficios que le reporta a los grupos de bajos ingresos un arriendo bien localizado. Hacer visible a este grupo de habitantes de la ciudad ha permitido observar sus ventajas espaciales y también su vulnerabilidad residencial, pero es necesario hacer notar que el arriendo constituye una forma de habitar, por lo que se debe reconocer su "propiedad territorial" (Del Acebo, 1996), esto es, la construcción de ciudad, barrio y de un lugar antropológico, más allá de la propiedad de una casa. En este sentido, una verdadera política de vivienda, en términos amplios, debería reconocer la capacidad e historia en la construcción del hábitat residencial en contextos de vulnerabilidad, entendido como la posibilidad de constituir un arriendo en propiedad.

\section{Bibliografía}

Alonso, L. E. (1998). La mirada cualitativa en sociología: una aproximación interpretativa. Madrid: Fundamentos.

Blanco, A. (2013). Política de arriendo y su incidencia en la promoción de residencias socialmente inclusivas. Seminario Internacional: Grandes líneas de la política urbana para la promoción de la integración social. Santiago: Centro de Políticas Públicas UC. Recuperado de http://politicaspublicas.uc.cl/ wp-content/uploads/2015/02/registro-seminario-grandes-lineas-de-politica-urbana-para-promocion-de-la-integracion-social.pdf

Blanco, A., Fretes, V. y Muñoz, A. (2014). Se busca vivienda en alquiler. Opciones de politica en América Latina y el Caribe. Recuperado de http://www. iadb.org/es/temas/desarrollo-urbano/viviendaen-alquiler/vivienda-en-alquiler,9546.html

Bourdieu, P. (2001). Las estructuras sociales de la economía. Buenos Aires: Manantial.

Brito, A. y Ganter, R. (2014). Ciudad obrera: persistencias y variaciones en las significaciones del espacio. El caso de la siderúrgica Huachipato y su influencia en el desarrollo urbano del Gran Concepción. EURE Revista Latinoamericana de Estudios Urbano Regionales, 40(121). doi:10.4067/ S0250-71612014000300002

Cáceres Seguel, C. (2015). Ciudades satélites periurbanas en Santiago de Chile: paradojas entre la satisfacción residencial y precariedad económica del 
periurbanita de clase media. Revista INVI, 30(85) doi:10.4067/S0718-83582015000300003

Contreras, Y. (2011). La recuperación urbana y residencial del centro de Santiago: Nuevos habitantes, cambios socioespaciales significativos. EURE Revista Latinoamericana de Estudios Urbano Regionales, 37(112), 89-113. doi:10.4067/ S0250-71612011000300005

Coulomb, R. y Sánchez, C. (1991). ¿Todos propietarios? Vivienda de alquiler y sectores populares en la ciudad de México. México DF: Centro de la Vivienda y Estudios Urbanos.

Davis, M. (2007). Planeta de ciudades miseria. Madrid: Foca.

Del Acebo, E. (1996). Sociología del arraigo. Una lectura crítica de la teoría de la ciudad. Buenos Aires: Claridad.

Gilbert, A. (1993). In seach of a home. Rental and shared housing in Latin America. Tucson: The University of Arizona Press.

Gilbert, A. (2011). Ten Myths Undermining Latin American Housing Policy. Revista de Ingeniería(35).

Gravano, A. (2005). El barrio en la teoría social. Buenos Aires: Espacio Editorial.

Greene, M., Link, F., Mora, R. y Figueroa, C. (2014). De la casa al barrio. ARQ (Santiago)(86), 78-87. doi:10.4067/S0717-69962014000100012

Gurvitch, G. (1953). La vocación actual de la sociología: hacia una sociología diferencial. México: Fondo de Cultura Económica.
I. Municipalidad de Valparaíso. (2009). Memoria Barrio Puerto. Proyecto de gestión de barrios históricos de ciudades puerto. Valparaíso: autor.

Inzulza-Contardo, J. (2012). 'Latino Gentrification'?: Focusing on Physical and Socioeconomic Patterns of Change in Latin American Inner Cities. Urban Studies, 49(10), 2085-2107. doi:10.1177/0042098011423425

Inzulza, J. y Galleguillos, X. (2014). Latino gentrificación y polarización: transformaciones socioespaciales en barrios pericentrales y periféricos de Santiago, Chile. Revista de Geografia Norte Grande(58), 135159. doi:10.4067/S0718-34022014000200008

Jimenez, C. y Fernandez, C. (2014). Casas sin gente, gente sin casas: el fracaso del modelo inmobiliario español. Revista INVI, 29(82), 133-155. doi:10.4067/ S0718-83582014000300005

Kapstein López, P. y Aranda Dioses, E. (2014). Las periferias interiores de Lima: localización e identificación de los barrios focos de vulnerabilidad. El caso de San Cosme. Revista INVI, 29(82), 19-62. doi:10.4067/S0718-83582014000300002

Katzman, R. (2000). Notas sobre la medición de la vulnerabilidad social $5^{\circ}$ Taller regional. La medición de la pobreza: métodos y aplicaciones (continuación) Aguascalientes, México, 6 al 8 de junio de 2000 (pp. 275-301): CEPAL

Krippendorf, K. (1990). Metodología de análisis de contenido: teoría y práctica. España: Grupo Planeta.

Lefebvre, H. (1969). El derecho a la ciudad. Barcelona: Editorial Península. 
Link, F., Marín Toro, A. y Valenzuela, F. (2015). La defensa del lugar y límites de los habitantes de Valparaíso y el Barrio Puerto. Proyecto sin publicar. Mini-COES (Centro de estudios de conflicto y cohesión social). CONICYT/FONDAP/15130009.

Link, F., Valenzuela, F. y Fuentes, L. (2015). Segregación, estructura y composición social del territorio metropolitano en Santiago de Chile: complejidades metodológicas en el análisis de la diferenciación social en el espacio. Revista de Geografia Norte Grande(62), 151-168. doi:10.4067/ S0718-34022015000300009

López-Morales, E., Arriagada-Luco, C., Gasic-Klett, I. y Meza-Corvalán, D. (2015). Efectos de la renovación urbana sobre la calidad de vida y perspectivas de relocalización residencial de habitantes centrales y pericentrales del Área Metropolitana del Gran Santiago. EURE Revista Latinoamericana de Estudios Urbano Regionales, 41(124), 45-67. doi:10.4067/S0250-71612015000400003

López Morales, E. (2013). Gentrificación en Chile: aportes conceptuales y evidencias para una discusión necesaria. Revista de Geografia Norte Grande(56), 31-52. doi:10.4067/S0718-34022013000300003

Madariaga, M. (2013). Los últimos habitantes del Astoreca. La juguera Magazine(2), 4-7.

Marcuse, P. (1985). Gentrification, abandonment, and displacement: connections, causes, and policy responses in New York city. Journal of Urban and Contemporary Law, 28, 195-240.
Margarit Segura, D. y Bijit Abde, K. (2014). Barrios y población inmigrantes: el caso de la comuna de Santiago. Revista INVI, 29(81), 19-77. doi:10.4067/ S0718-83582014000200002

Marín Toro, A. (2015). Paradoja de la vivienda en arriendo: arraigo y vulnerabilidad residencial en el Barrio Puerto de Valparaíso. (Magíster en Desarrollo Urbano), Pontificia Universidad Católica de Chile, Santiago.

Márquez, F. (2014). Inmigrantes en territorios de frontera: la ciudad de los otros. Santiago de Chile. EURE (Santiago), 40(120), 49-72. doi:10.4067/ S0250-71612014000200003

Mayol, P. (1999). ¿Qué es un barrio? En M. d. Certeau (Ed.), La invención de lo cotidiano 2 (pp. 5-12). México DF: Universidad Iberoamericana.

Mora, P. (s.f.). Arrendamiento en los hogares vulnerables: ¿sólo déficit de vivienda o demanda? Recuperado de http://blog.latercera.com/blog/piamora/entry/ arrendamiento_en_los_hogares_vulnerables

Reid, C. (2013). To buy or not to buy? Understanding tenure preferences and the decision-making processes of lower income housholds. Recuperado de: http:// www.jchs.harvard.edu/sites/jchs.harvard.edu/files/hbtl-14.pdf

Roch Peña, F. (2007). La ciudad histórica como lugar para la convivencia. Inmigración y vida urbana en el barrio de Lavapiés de Madrid. Madrid: Departamento de Urbanística y Ordenación del Territorio de la ETSAM. 
Sabatini, F., Brain, I. y Mora, P. (2012). Mercado del arriendo en Chile. Washington: Programa ProUrbana del Centro de Políticas Públicas UC, BID.

Saucedo, I. A. y Taracena, B. E. (2011). Habitar la calle: pasos hacia una ciudadanía a partir de este espacio. Revista Latinoamericana de Ciencias Sociales, Niñez y Juventud, 9(1), 269-285.

Simmel, G. (2005). La metrópolis y la vida mental. Bifurcaciones, (4). Recuperado de http://www.bifurcaciones.cl/2005/09/la-metropolis-y-la-vida-mental/

Smith, N. (2012). La nueva frontera urbana. Ciudad revanchista y gentrificación. Madrid: Traficantes de Sueños.

Soja, E. (2010). Seeking Spatial Justice. Minneapolis: University of Minnesota Press.

Taylor, S. y Bogdan, R. (1987). Introducción a los métodos cualitativos de investigación. Barcelona: Paidós.

UNESCO World Heritage Centre. (s.f.) Historic quarter of seaport city of Valparaíso. Recuperado de http://whc.unesco.org/en/list/959

University of Chicago. (2014). Kenneth Jackson I Keynote Address. Recuperado de https://www.youtube.com/watch? $\mathrm{v}=\mathrm{kmDw} / \mathrm{zdqJvY}$

Urbina, X. (2011). Los conventillos de Valparaíso 18801920. Fisionomía y percepción de una vivienda popular urbana (2a ed.). Valparaíso: Ediciones Universitarias de Valparaíso.

Valles, M. (1999). Técnicas cualitativas de investigación social. Reflexión metodológica y práctica profesional. Madrid: Síntesis.
Vergara Constela, C. y Casellas, A. (2016). Políticas estatales y transformación urbana: ¿hacia un proceso de gentrificación en Valparaíso, Chile? EURE Revista Latinoamericana de Estudios Urbano Regionales, 42(126), 123-144. doi:10.4067/ S0250-71612016000200006

Wiese, A. (2004). Places of their own: African American Suburbanization in the Twentieth Century. Chicago: University of Chicago Press.

Wirth, L. (2005). El urbanismo como modo de vida. Bifurcaciones(2).

Zamora, R. (2013). El Barrio Puerto se prepara para ponerse guapo. El Mercurio de Valparaíso, pp. 1011. Recuperado de http://www.mercuriovalpo.cl/ impresa/2013/05/05/full/46/

Zukin, S. (2011). Naked city. The death and life of authentic urban places. New York: Oxford University Press. 